\title{
PC4 and SFRS1-Interacting Protein Isoform 1
}

National Cancer Institute

\section{Source}

National Cancer Institute. PC4 and SFRS1-Interacting Protein Isoform 1. NCI Thesaurus. code 134097

PC4 and SFRS1-interacting protein isoform 1 (530 aa, $60 \mathrm{kDa}$ ) is encoded by the human PSIP1 gene. This protein plays a role in transcriptional regulation, neurogenesis and HIV infection. 